\title{
"INVICTUS" - INTEGRAÇÃO RACIAL NA ÁFRICA DO SUL E O PODER POLÍTICO DO ESPORTE
}

\author{
André Mendes Capraro \\ Universidade Federal do Paraná, Curitiba, Paraná, Brasil \\ Cristina Carta Cardoso de Medeiros \\ Universidade Federal do Paraná, Curitiba, Paraná, Brasil \\ Riqueldi Straub Lise \\ Universidade Federal do Paraná, Curitiba, Paraná, Brasil
}

Quando Invictus entrou em cartaz no circuito nacional, as atenções
já estavam voltadas para a África do Sul, pois restavam poucos meses para realização a da Copa do Mundo FIFA de 2010, no país africano. Mesmo não tratando da prática do futebol, e sim do rúgbi, o filme, adaptação do livro de John Carlin Conquistando o Inimigo, gerou interesse tanto pela curiosidade geral de conhecer o palco de um megaevento esportivo, quanto na sequência dos acontecimentos que envolveram seus protagonistas. No filme e no livro, há a tentativa de apresentar o rúgbi - esporte elitizado, carregado de valores éticos do olimpismo - como símbolo da repressão do antigo regime do Apartheid, bem como uma modalidade que serviu de elemento agregador e, portanto, formador de uma identidade nacional, mobilizador de massas e moldador de percepções políticas.

De forma sintética, o enredo principal do filme, dirigido por Clint Eastwood, mostra Nelson Mandela (interpretado por Morgan Freeman) já presidente da África do Sul, lidando com as dificuldades e tensões da transição política, na tentativa de agregar a população branca e negra, por meio do Mundial de Rúgbi, que ocorreu no ano de 1995 no próprio país. Para tanto, Mandela utiliza seu capital político e o talento de ganhar adeptos à sua causa apelando para as melhores qualidades, a partir do contato pessoal fundamental (que despertou a admiração mútua) com o capitão do selecionado nacional sul-africano, François Pienaar (Matt Damon). Estimulado por tal influência, Pienaar contagia seus companheiros de equipe, obtendo a vitória no torneio internacional. 
Porém, tal história verídica, recriada e reproduzida por meio da arte/tecnologia cinematográfica, necessitou de alguns "esquecimentos", omissões e manipulações para não comprometer o enredo clássico um grande desafio, uma grande dificuldade e o desenrolar pautado nas iniciativas do herói e da vitória como desfecho. Como típica produção da indústria do entretenimento hollywoodiana, Invictus reduz todo o desvelar da sucessão de um regime de exclusão racial à necessidade da vitória nos gramados de um estádio de rúgbi, portanto, é um prazeroso entretenimento ao público, mas limitador da experiência histórica. Como bem ressalta Keller (2008), que acredita que a África do Sul ainda está a uma ou duas gerações da reconciliação racial, a premissa de que um único jogo de rúgbi, mesmo um jogo do campeonato mundial, poderia curar três séculos de divisão racial, dissipando terrores e ódios acumulados é uma ideia romântica, embora depoentes da época afirmem que foi um momento formativo para a nação e para afastar o país da ameaça de uma guerra civil.

O rúgbi e o críquete eram os esportes prediletos da elite dominante branca - os africâneres -, porém, não necessariamente excluídos do gosto popular. Tampouco existia uma oposição em relação ao futebol, esporte mais popular entre a maioria negra do país (como apresentado, por exemplo, no filme No Futebol, Nasce Uma Esperança), já que este também era uma modalidade de origem britânica, ou seja, a gênese colonialista do esporte não era um bom motivo para o completo desdenho.

A resistência se dava em outros campos, pois, se assim o fosse, o ressentimento seria também contra o futebol, o esporte mais popular da Inglaterra e demais países da Europa Ocidental. O rúgbi também era apreciado por alguns indivíduos negros de diferentes classes sociais do país. Inclusive, frequentar estádios era uma das formas de demonstrar a vigência da nova política de igualdade racial, já que anteriormente só era permitida nas arquibancadas a presença de brancos. Da mesma forma, também não eram raros os brancos aficionados por futebol.

No filme Invictus, que neste aspecto é fiel à narrativa do livro de Carlin, a dicotomia é clara: o rúgbi é branco, elitista e segregador, enquanto o futebol é negro, popular e inclusivo. Na metáfora exposta logo no início da película, Mandela seria o único elo entre as atividades elitistas e populares. Mas, para tanto, necessitaria se esforçar bastante, já que a minoria branca, ainda detentora de elevado grau de poder, o 
via com certa desconfiança. É aí que transparece o habitus político de Mandela.

A estratégia política sempre esteve presente, por isso há a percepção de algumas lacunas no roteiro do filme, quando se trata de uma análise mais fiel da conjuntura, recuperadas na narrativa de John Carlin. Mandela em um comício chegou a ser vaiado quando portou um boné dos Springboks. Nesta ocasião, argumentou que seus críticos não deveriam ser emocionais, e que construir uma nação significava para brancos e negros, o pagamento de um preço. "Ao abrirem os esportes para os negros, eles estão pagando um preço; ao dizermos que agora temos que apoiar o time de rúgbi, estamos pagando um preço. É isso que devemos fazer (CARLIN, 2009, p.205).

O segundo e mais importante aspecto "omitido" no filme: os springboks (alcunha dos atletas do selecionado sul-africano) eram considerados, há algum tempo, um dos melhores times do mundo, sendo inclusive candidato ao título daquela temporada. A ideia manifesta no filme, e sem dúvida incorporada por vários espectadores menos familiarizados com o esporte, é a de que o selecionado da África do Sul seria um mero coadjuvante no torneio, pois era pouco representativo no cenário global, quando, na verdade, o problema naquele período seria uma pequena queda de rendimento nos anos que antecederam ao Mundial. Prova é que o próprio Mandela, sempre assertivo, confiava no desempenho dos Springboks e, como afirmou em vários momentos, confiava também no poder do esporte de inspirar, de unir pessoas que têm pouco em comum, sendo, em sua opinião, mais poderoso que os governos para derrubar barreiras raciais.

Em terceiro lugar, a relação entre Nelson Mandela e François Pienaar é supervalorizada no filme. É comum políticos de alto escalão usarem o esporte para um acréscimo na sua própria imagem (Mandela, por exemplo, adorava aparições repentinas em locais com grande público - tal como um estádio esportivo). Porém, o filme ressalta que os encontros resultaram em um forte laço afetivo de amizade, quando, em essência, não passava dos "não tão raros" encontros entre atletas de destaque, presidentes e primeiros-ministros, ainda mais em véspera de eventos mundiais de grande cobertura midiática.

Desta forma, apenas nuances da complexidade das relações ocorridas durante o regime pós-Apartheid puderam ser vislumbradas por meio do roteiro de Invictus. $O$ único atleta negro na equipe sul-africana, por exemplo, Chester Williams, nitidamente no filme, se abstinha 
quando questionado acerca do seu posicionamento político/racial. Quando interpelado, Wiliams era esquivo, justificando que tal discussão não pertencia ao campo esportivo. O mesmo pode se aplicar, genericamente, aos demais atletas. Alienados quanto ao processo de democratização recentemente ocorrido, que culminaria com a eleição de Nelson Mandela, com uma única exceção, todos os atletas eram brancos e estavam mais preocupados com esporte do que com política.

O próprio Pienaar, em meio à alienação (proposital) típica dos atletas do selecionado sul-africano, vivia um conflito acerca da sua etnicidade, condição racial e política nacional no seio da sua própria família. Esta via inicialmente com restrições o ideário sócio-político difundido por Nelson Mandela, passando a admirá-lo somente a partir do contato pessoal com o atleta representante da família. E se a família de origem branca de Pienaar apresentava certo receio da política de integração racial proposta pelo emblemático Mandela, não seria diferente - por sinal, em proporções bem maiores - a desconfiança dos correligionários partidários que exerciam funções governamentais em relação ao uso do selecionado nacional de rúgbi como elemento agregador sócio-racial. Sendo necessária, como exibido no filme, a intervenção enérgica do próprio Mandela.

É exatamente neste posicionamento que reside o mérito de Nelson Mandela no caso. Investir em uma modalidade esportiva tipicamente branca como forma de agregação era, sem dúvida, um risco político sério. Nelson Mandela não teve receio em enfrentá-lo. Um traço da personalidade de Mandela era exatamente passar a falsa impressão de que era impulsivo, mesmo que suas decisões, quase sempre moderadas, fossem tomadas pela razão, a partir dos indicativos das possíveis consequências. Perfil que gerou a figura de um "líder carismático" dos mais conhecidos em toda a história da humanidade da humanidade. Assim, Mandela analisou as possibilidades e apostou pesado na máxima da integração racial por meio do esporte.

A "leitura" de que aquele esporte em específico poderia propiciar uma conquista que criaria um sentido de pertencimento nacional, reforçando a ideia de igualdade racial, em um país que vivera por décadas sob a égide de uma minoria branca, é o que permite afirmar, a partir do exemplo tratado no filme, que Nelson Mandela era um sujeito visionário. Quem sabe também tenha sido auxiliado pelas próprias características do esporte em questão. Como bem recuperado por Carlin (2009), o rúgbi pode ser um jogo empolgante, mesmo para quem 
não está familiarizado com sua complexidade. Combina tática, força e velocidade em um espetáculo agressivo e ao mesmo tempo agradável de assistir. Nenhum esporte, segundo o autor - em termos de dor infligida e brutalidade de colisão - está mais perto da guerra. Assim, o rúgbi, como catalisador e unificador do patriotismo, coadunado à orquestração de Mandela e o slogan "um time, um país", fizeram dos jogadores agentes políticos, assertiva que culmina com a fala de Piennar quase ao final do jogo: "Olhem em torno... estão vendo aquelas bandeiras? Joguem para esse povo. É uma oportunidade única. Temos que fazer isso pela África do Sul. Vamos ser campões do mundo" (CARLIN, 2009, p. 246).

A produção tem seu desfecho com a conquista do título de campeão mundial de rúgbi pelo selecionado sul-africano diante da equipe da Nova Zelândia em 24/06/1995, com a presença de Nelson Mandela no estádio, o qual confiava na conquista do evento para aproximar a maioria negra da minoria (mas por muito tempo detentora do poder) branca. Para tal missão, o dirigente contou com o apoio de Fraçois Pienaar, capitão e líder dos Springboks. Ou seja, parece que afetivamente o problema racial fora resolvido. Porém, a sequência dos fatos não corrobora o acontecido no filme: mesmo com todo o ufanismo predominante após a vitória no mundial, alguns problemas sócio-raciais existentes desde o regime do Apartheid voltaram à tona. E mesmo que o rúgbi deixasse de ser considerado um esporte de "representação branca", ainda continuou sendo praticado essencialmente por brancos. Em se tratando das torcidas, as alterações foram mais sutis do que os resultados apresentados no filme, já que o rúgbi - embora não seja símbolo de opressão racial - ainda é a modalidade de preferência da população branca, bem como o futebol é o esporte preferido pelos cidadãos sul-africanos negros.

\section{Referências}

KELLER, B. Entering the Scrum. Sunday Book Review. The New York Times. Disponível em: http://www.nytimes.com/2008/08/17/books/review/Keller-t.html?_r=1. Acessado em 01/03/2012.

CARLIN, J. Invictus, Conquistando o Inimigo: Nelson Mandela e o jogo que uniu a África do Sul. Rio de Janeiro: Sextante, 2009. 270 p. 


\section{Fontes}

Filme Longa Metragem em DVD INVICTUS. Direção: Clint Eastwood. Interpretes: Morgan Freeman, Matt Damon e outros. Produção: EUA: Warner Brothers, 2010. 134 min.

Recebido em: 06/06/2012

Revisado em: 10/07/2012

Aprovado em: 07/08/2012

\section{Endereço para correspondência}

andrecapraro@onda.com.br

André Mendes Capraro

Universidade Federal do Paraná, Departamento de Educação Física.

Rua Coração de Maria, 92 - BR 116 km 95

Campo Comprido

80215-370 - Curitiba, PR - Brasil 